\title{
ESTADO DA ARTE DAS PESQUISAS COM O CARANGUEJO-UÇÁ, Ucides cordatus
}

\section{The state of the art of the research on the mangrove land crab, Ucides cordatus}

\author{
CASTILHO-WESTPHAL, G.G. ${ }^{1,2}$; OSTRENSKY, A. ${ }^{1,2}$; PIE, M.R. ${ }^{1,3}$; BOEGER, W.A. ${ }^{1,3}$ \\ ${ }^{1}$ Grupo Integrado de Aqüicultura e Estudos Ambientais - UFPR \\ ${ }^{2}$ Departamento de Zootecnia - UFPR \\ ${ }^{3}$ Departamento de Zoologia - UFPR
}

Endereço para correspondência: Grupo Integrado de Aqüicultura e Estudos Ambientais, CP 19073, Universidade Federal do Paraná, Curitiba, PR. CEP 81531-990, Brasil. Fone: +55 (41) 3350-5634.

Fax: +55 (41) 3350-5634. E-mail: xlcastilho@yahoo.com.br

\section{RESUMO}

Pertencente a Ocypodidae, o caranguejo-uçá, Ucides cordatus, é uma espécie endêmica da costa atlântica do Continente Americano. Possui grande importância econômica, principalmente para populações de baixo poder aquisitivo, que dependem de sua captura como fonte de renda e alimento. U. cordatus é considerado um dos componentes biológicos mais importantes do ecossistema dos manguezais por seu papel na ciclagem de matéria orgânica. Possivelmente, em virtude do intenso esforço de captura somado à destruição de seus habitats - os manguezais - e a uma enfermidade específica (Doença do Caranguejo Letárgico), têm-se observado uma tendência de redução dos estoques pesqueiros de caranguejo-uçá no litoral brasileiro. Porém, a despeito de sua importância cultural, ecológica e sócio-econômica, o número de pesquisas científicas desenvolvidas com a espécie ainda é limitado. O objetivo deste trabalho foi identificar e apresentar os principais estudos publicados sobre a espécie até o ano de 2007.

Palavras-chave: crustáceo; Ocypodidae; Brachyura; caranguejo; manguezal.

\section{ABSTRACT}

A member of Ocypodidae, the mangrove land crab, Ucides cordatus, is endemic to the Atlantic Coast of the Americas. It has considerable economic value mainly to underpriviledged communities, which depend on it as a source of income and food. $U$. cordatus is considered as one of the most important biological components of mangrove ecosystems, particularly due to its role in the cycling of organic matter. Possibly as a consequence of the intense harvesting, the destruction of its habitats - the mangroves and disease, there has been a decrease in the fishery stocks of the mangrove crab throughout the Brazilian coast. However, in spite of the cultural, ecological, and socioeconomic importance of the species, the number of scientific studies on the mangrove land crab is still limited. The aim of the present study is to identify and relat the main studies published on the species until 2007.

Key words: crustacean; Ocypodidae; Brachyura; crab; mangrove. 


\section{INTRODUÇÃO}

As primeiras referências sobre 0 caranguejo-uçá (figura 1) são anteriores a Linnaeus, feitas por Souza (1587 apud Costa, 1979) e, posteriormente, por Marcgrave (1648) apud Costa (1979). Ucides (Rathbun, 1897), inicialmente incluído como membro de Gecarcinidae, foi reclassificado como Ocypodidae por Chance e Hobbs (1969) devido a uma maior similaridade morfológica com espécies dessa família. Ucides engloba duas espécies, Ucides cordatus (Linnaeus, 1763) e Ucides occidentalis (Ortmann, 1897) (Bright e Hogue, 1972). Uma classificação, embasada em observações fenotípicas (Bright e Hogue, 1972; Pinheiro e Fiscarelli, 2001) e na distribuição geográfica, considera que Ucides é monotípica e apresenta duas subespécies, Ucides cordatus occidentalis (Ortmann, 1897) e U. cordatus cordatus (Linnaeus, 1763) (Diele, 2000; Rodrigues e Hebling, 1989; Spivak, 1997).

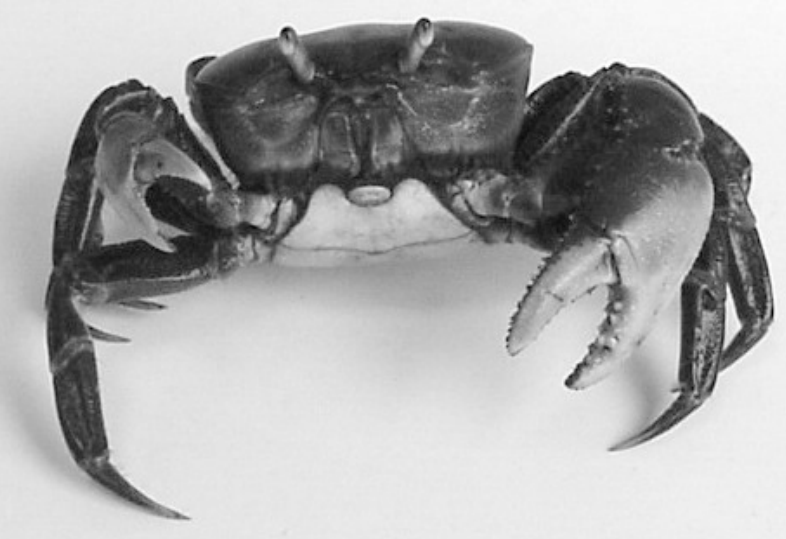

Figura 1 - Exemplar de Ucides cordatus (caranguejo-uçá). Fonte: grupo integrado de aqüicultura e estudos ambientais.

Ucides cordatus, popularmente conhecida no Brasil como caranguejo-uçá, catanhão, caranguejo do mangue ou caranguejo-verdadeiro (Branco, 1993; Nordhaus, 2003), foi registrada pela primeira vez no litoral brasileiro no início do século XIV por jesuítas e viajantes portugueses (Melo, 1996). Endêmico da costa atlântica do Continente Americano, o caranguejo-uçá, U. cordatus (Crustacea, Brachyura, Ocypodidae), tem uma distribuição geográfica que abrange os manguezais desde a Flórida (E.U.A.) até Santa Catarina (sul do Brasil) (Costa, 1979; Mello, 1996; Blankensteyn et al., 1997; Spivak, 1997; Diele, 2000; Silva, 2002).

Considerando a importância ecológica e sócioeconômica da espécie, a presente revisão tem por objetivo apresentar e discutir os principais estudos publicados sobre o caranguejo-uçá, U. cordatus, até meados de 2007.

\section{FISIOLOGIA E ULTRAESTRUTURA}

Ucides cordatus é um organismo marcantemente eurihalino (Martinez et al., 1998). Esse caranguejo faz incursões à superfície do solo durante a maré baixa para limpar ou construir sua toca e se alimentar, por várias horas e sem estar imerso em água. A capacidade de manutenção da homeostase nessa espécie é atingida pela presença de um eficaz mecanismo osmorregulatório presente nas brânquias posteriores (Martinez et al., 1999).

Em crustáceos Brachyura a $\mathrm{Na}^{+}+\mathrm{K}^{+}-$ ATPase é responsável pela passagem por movimento transepitelial de íons monovalentes, principalmente através das brânquias posteriores. $\mathrm{A} \mathrm{Na}^{+}+\mathrm{K}^{+}$-ATPase é encontrada predominantemente em células ricas em mitocôndrias as quais são morfológica e bioquimicamente especializadas em mediar $\mathrm{NaCl}$, sugerindo seu envolvimento no transporte de tecidos e, por conseguinte, na capacidade de $U$. cordatus invadir ambientes estuarinos (Turkin, et al., 1992; Lucu e Towle, 2003).

A regulação iônica e sua influência sobre parâmetros urinários e hematológicos são fundamentais no estudo 
de aspectos fisiológicos de $U$. cordatus, sendo alvo de diversos estudos, como os realizados por Martelo e Zanders (1984); Santos e Salomão (1985a); Santos e Salomão (1985b); Turkin et al.(1992); Harris e Santos (1993); e, Harris e SANTOS (2004). A produção urinária de $U$. cordatus é $60 \%$ mais elevada em meio diluído (água salobra com 0,9 de salinidade) do que em água salgada $(3,5$ de salinidade). A glândula antenal, quando em meio diluído, regula o volume da hemolinfa e a perda de solutos, excretando potássio, magnésio e cálcio. Além disso, nessa espécie, a reduzida perda de sódio, associada à redução no fluxo urinário, evita a perda excessiva de líquidos (Santos, 1987).

O magnésio é ativamente excretado na urina. Essa excreção se intensifica a medida em que há elevação de temperatura. A regulação de sulfato na hemolinfa, em contrapartida, é pouco influenciada pela temperatura de aclimatação e a taxa de secreção de sulfato é menor que a de magnésio, não se elevando com o acréscimo de temperatura Zanders e Martelo (1984).

Ucides cordatus possui dois tipos de grânulos eletrodensos (GED) no hepatopâncreas - estrutura encontrada em vários tecidos de organismos vertebrados e invertebrados: os mineralizados e os não mineralizados (CORRÊA Jr. et al., 2003). Os GED não mineralizados são encontrados, principalmente, dentro de vacúolos que reagem positivamente com a fosfatase ácida e o ácido D-amino oxidase, os quais possibilitam a degradação de lipídios de membrana. Allodi et al. (2002) sugeriram que há uma associação entre retículo endoplasmático e a gênese da mineralização de GED. Para esses autores, parece existir uma associação entre a capacidade de estocagem de cálcio e de fósforo pelos caranguejos e a síntese de uma nova carapaça. Entretanto, as concreções de minerais amorfos podem estar relacionadas ao fenômeno de retenção de cátions de metais pesados do ambiente em $U$. cordatus.

A microscopia eletrônica revelou, em $U$. cordatus, a existência de tipos celulares denominados de células gliais (CG) escuras e claras. As CG escuras correspondem às células perineurais, localizadas na base dos neurônios. As CG claras, por sua vez, correspondem às células periaxonais. Acredita-se que as CG processem um material denso $\mathrm{e}$ homogêneo, que atue como isolante, como ocorre com a bainha de mielina em vertebrados. Esta especialização das CG pode ser responsável pela capacidade de condução de impulsos nervosos em alta velocidade em crustáceos (Allodi e Taffarel, 1999).

\section{REPRODUÇÃO}

Góes et al. (2000), estudando o comportamento reprodutivo de $U$. cordatus, definiram a ocorrência de quatro eventos principais relacionados à reprodução: a) caranguejo espumando (evento observado apenas em machos, que produzem uma espuma branca na região acima dos terceiros maxilípedes, na altura dos meropoditos, exalando odor característico de caranguejo por todo o mangue); b) andada para acasalamento (comportamento pré-copulatório caracterizado por grande movimentação e batalhas entre machos, machos e fêmeas e entre fêmeas); c) acasalamento (observado na entrada das galerias, ocorre quando macho e fêmea permanecem entrelaçados ventre a ventre); d) liberação das larvas (que, no caso estudado pelo autor ocorreu durante todo o período de baixa-mar, nas margens dos canais de maré, quando as fêmeas abrem e fecham o abdome várias vezes enquanto liberam um líquido da região acima dos terceiros maxilípedes sobre os ovos, cuja função ainda é desconhecida).

Com referência à andada, Costa (1979) descreveu que, em determinados 
períodos do ano, parte dos indivíduos da população de $U$. cordatus que habita manguezais de Fortaleza, Ceará, abandona as galerias por 2 ou 3 dias sucessivos, geralmente coincidentes com as mais baixas marés do mês, quando vagueiam por toda a área do manguezal. Sant'anna (2006) identificou uma correlação positiva entre a "andada" e o aumento da luminosidade $e$ maiores amplitudes de maré. Fatores ambientais também influenciam o início e o final do processo de muda, o qual ocorre quando a amplitude entre as marés alta e baixa começa a diminuir (maré de quebramento). O processo de muda dessa espécie, em seu habitat natural, dura em torno de 28 a 29 dias, período em que o caranguejo permanece entocado até que a carapaça esteja completamente enrijecida (Alves e Nishida, 2002).

Segundo Costa (1979), durante o período de andada ou "carnaval", os indivíduos de ambos os sexos se deslocam desordenadamente de um lado para outro, perseguindo-se mutuamente. A formação de casais inicia com a entrada da fêmea em uma toca abandonada, seguida por um macho que a puxa pelo quelípode até a superfície. Então, tem-se início a côrte, que se caracteriza pela movimentação dos quelípodes - tanto o macho quanto a fêmea lançam os quelípodes sobre seu parceiro - que finaliza com a cópula (acasalamento).

A reprodução tem caráter sazonal, seguindo um ritmo estritamente lunar. As fêmeas liberam as larvas nos manguezais inundados no estofo de maré, precedendo as marés vazantes, com os picos de eclosão sempre ocorrendo antes da lua nova (Diele, 2000). O crescimento segue um padrão indeterminado, com aumentos relativos de crescimento e freqüência de muda diminuindo distintamente com 0 tamanho. Ucides cordatus é uma espécie de Brachyura longeva, com um período máximo de vida de mais de dez anos e fêmeas alcançando a maturidade sexual em torno de 2,1 a 3,0 anos (Diele, 2000; Pinheiro et al., 2005). Ambos os sexos apresentam quatro morfotipos: juvenil, prépuberdade, sub-adulto e adulto (Pinheiro e Hattori, 2006).

A morfologia gonadal, macro e microscópica, assim como o estudo do ciclo reprodutivo, têm sido alvo de estudos por diversos autores. Alves (1975) descreveu a morfologia dos aparelhos reprodutores masculinos e femininos, além do acasalamento e o período reprodutivo do caranguejo-uçá no Ceará (Brasil). Nakamura (1979) estudou a fenologia de $U$. cordatus oriundos da Baía de Paranaguá. A observação de aspectos macroscópicos dos ovários e as variações da relação gonadossomática do caranguejo-uçá permitiu a Góes et al. (2000) definir o período reprodutivo nos manguezais da Baía de Vitória (Espírito Santo, Brasil) entre os meses de dezembro a maio. O período reprodutivo de $U$. cordatus também foi objeto de estudo por Dalabona (2001) e Dalabona et al. (2005), que pesquisaram espécimens das llhas do Pavoça e das Peças (Paraná, Brasil).

Castilho (2006) e Castilho, et al. (2008) identificaram em U. cordatus machos adultos seis tipos celulares durante a espermatogênese. Os autores reconheceram as seguintes regiões do aparelho reprodutor masculino: testículos, vasos deferentes (anterior, médio e posterior), ductos ejaculadores e dois pênis. Nas fêmeas, a classificação dos estágios de maturação ovariana foi desenvolvida a partir de modificações ovocitárias durante a vitelogênese. Variações nos padrões de vitelogênese observadas em algumas fêmeas sugerem a possibilidade de haver mais de uma desova num mesmo período reprodutivo. O período reprodutivo de $U$. cordatus nos manguezais da Baía de Antonina estendeu-se de outubro a março, havendo fêmeas ovígeras geralmente de novembro a fevereiro (Castilho, 2006). Pinheiro et al. (2000) verificaram um pico de fêmeas com ovários 
maturos em manguezais de Iguape/SP, no mês de novembro, seguido pela maior ocorrência de fêmeas ovígeras de dezembro a fevereiro.

A fecundação, provavelmente, é interna e ocorre durante a ovoposição. Fêmeas de $U$. cordatus são capazes de manter espermatozóides viáveis armazenados em suas espermatecas por vários meses ou, pelo menos, por um ano (Castilho, 2006). Histoquimicamente, a secreção da parede da espermateca é fortemente positiva para polissacarídeos neutros e polissacarídeos ácidos e fracamente positiva para proteínas e lipídios. Esta secreção forma a matriz glicoprotéica, que possibilita a manutenção dos espermatóforos estocados por longos períodos (Sant'anna et al., 2007).

Ostrensky et al. (1995), em estudos realizados no litoral paranaense, verificaram que $U$. cordatus não respondeu positivamente ao processo de ablação do pedúnculo ocular, comumente utilizado em laboratórios comerciais de reprodução de camarão marinho para acelerar o processo de maturação gonadal. Contrariamente ao esperado, os exemplares submetidos à ablação não apresentaram aumento da freqüência de desovas, mas uma redução significativa no número de ovos produzidos.

Segundo Hattori e Pinheiro (2003a) e Pinheiro et al. (2003), a fertilidade de fêmeas de caranguejo-uçá, em condições de laboratório, varia de 71200 a 220800 larvas, valores que apresentam correlação positiva com a largura de carapaça. Hattori (2002) e Hattori e Pinheiro (2003a) também observaram que o processo de eclosão, que ocorre preferencialmente à noite, é menor em fêmeas cuja largura de carapaça é maior, o que possivelmente está associado à redução de espermatóforos na espermateca ou à senilidade das fêmeas.

Pinheiro e Hattori (2003b) também observaram, em condições de laboratório, que os ovos do caranguejo-uçá tendem a se tornar ligeiramente elipsoidais com o desenvolvimento embrionário, aumentando em 13,9\% seu diâmetro e 91,7\% em volume. Distinguem-se três grupos diferentes para o diâmetro (estágios III, III$\mathrm{VI}$, e VII-VIII) e para o volume (estágios IIII, IV-V-V, e VI-VIII), adotando-se como classificação dos embriões os estágios: inicial, intermediário e final, que também são usados atualmente nos estudos da biologia reprodutiva de outros crustáceos decápodes. Segundo esses autores, a identificação dos diferentes estágios embrionários de $U$. cordatus é possível somente se os dados biométricos forem combinados à observação da morfologia interna dos embriões e da coloração dos ovos. Essa modificação gradual na tonalidade ocorre à medida que ocorre o desenvolvimento embrionário durante a incubação dos ovos presos aos apêndices abdominais (pleópodes) das fêmeas, por cerca de 28 a 30 dias (Rodrigues, 1982).

$O$ desenvolvimento larval de $U$. cordatus envolve seis estádios zoea e um de megalopa, não sendo observado estádio pré-zoea (Rodrigues, 1982; Rodrigues e Hebling, 1989). Após a ecdise da megalopa, origina-se o primeiro estádio juvenil do caranguejo-uçá. Neste estádio os exemplares têm tamanho reduzido de cerca de $1,5 \mathrm{~mm}$ de largura de cefalotórax (Diele, 2000).

As eclosões de larvas zoea ocorrem de forma sincronizada. As fêmeas desovam nos manguezais inundados, no estofo de maré, antes das marés vazantes e os picos de desova ocorrem, geralmente, um dia antes da lua nova. Durante os picos de desova, observam-se densidades iniciais de zoea I que chegam a 23000 larvas $/ \mathrm{m}^{3}$. Os estádios seguintes de zoea, dependendo das condições geográficas locais, podem permanecer em zonas estuarinas durante as suas três ou quatro semanas de desenvolvimento (Diele, 2000); ou apresentam mecanismos de dispersão afastando-se dos manguezais das populações parentais em direção à costa (Freire, 1998). 
Salinidades letais $(\leq 10)$ ocorrem freqüentemente em estuários durante as estações reprodutivas. Isto sugere uma necessidade de exportação larval para regiões mais distantes de águas costeiras, onde há águas mais salinas, propiciando significativa sobrevivência larval e manutenção da viabilidade populacional (Diele e Simith, 2006). Essa estratégia de exportação de larvas, durante toda a história evolutiva de $U$. cordatus, resultou na ausência de diferenciação genética entre populações, mesmo separadas por grandes distâncias na costa brasileira (Oliveira-Neto et al., 2007a, Oliveira-Neto et al., 2007b).

O recrutamento de larvas de $U$. cordatus é fortemente influenciado por odores co-específicos dos mangues, ou seja, odores de $U$. cordatus e de outras espécies de caranguejos que, possivelmente, indicam locais cujas condições ambientais são favoráveis para a colonização das megalopas (Diele e Simith, 2007).

A reprodução e larvicultura de $U$. cordatus em ambiente de laboratório tem sido desenvolvida experimentalmente desde 2000, pelo Grupo Integrado de Aqüicultura e Estudos Ambientais (GIA) da Universidade Federal do Paraná. Inicialmente estes estudos fizeram parte de um projeto de recomposição populacional das áreas potencialmente afetadas pela Refinaria Duque de Caxias-RJ (Silva, 2002), sendo, posteriormente, implantados no litoral paranaense com objetivo de repovoar áreas alteradas.

Atualmente, o cultivo dessa espécie é realizado através da obtenção de fêmeas ovígeras no ambiente e a realização das etapas de eclosão, desenvolvimento larval e obtenção de juvenis, em laboratório. Embora ainda existam muitas lacunas a serem preenchidas para o completo domínio das etapas da tecnologia de reprodução e larvicultura do caranguejouçá em laboratório, a pesquisa tem avançado com 0 desenvolvimento de inúmeros estudos (Silva, 2002; Castilho, 2006; Costa, 2006; Ventura, 2006; Silva, 2007; Becker, 2008; Castilho et al., 2008; Ventura et al., 2008; Ventura et al., no prelo).

\section{ECOLOGIA E COMPORTAMENTO}

Encontrado exclusivamente em manguezais, $U$. cordatus habita regiões de mesolitoral e de supra-litoral, em substratos macios, onde constrói tocas com uma profundidade máxima de 2 metros. As tocas são construídas abaixo do mais alto nível de maré alta, tem aspecto uniforme, geralmente rasas, relativamente em linha reta e freqüentemente com múltiplas entradas, que se cobrem diariamente, com a elevação de maré (Bright e Hogue, 1972).

Os caranguejos permanecem dentro das tocas quando submersas, obtendo proteção contra predadores e contra a dessecação (Nordhaus, 2003). A observação de aspectos etológicos de $U$. cordatus revela como comportamentos mais comuns: a) limpeza das galerias, quando parcialmente inundada; b) fuga do contato com os seres humanos. caranguejo-uçá apresenta comportamento territorialista, construindo galerias individuais que são intensamente protegidas contra invasores por seus habitantes (Costa, 1979; Garcia de Geraldes e Bonnelli de Calventi, 1983; Branco, 1993). No entanto, a competição local entre caranguejos provoca uma maior movimentação e mudança de tocas (Piou et al., 2007).

O recrutamento do caranguejo-uçá ocorre em zonas pouco alagadas, principalmente nos apicuns, particularmente dentro de galerias de indivíduos maiores (Schmidt et al.,2005). Segundo Hattori (2006), manguezais com predominância de Rhizophora mangle apresentaram maior potencial extrativo $(85,7 \%)$ de $U$. cordatus, seguida por Avicennia schaueriana $(79,3 \%)$ e menor em Laguncularia racemosa (34,3\%). Áreas de 
L. racemosa, por apresentar em elevada abundância de $U$. cordatus de pequeno porte, devem ser preservadas $e$ consideradas como uma reserva dos estoques naturais desse recurso.

A umidade do sedimento, o enraizamento, o diâmetro a altura do peito e a altura das árvores influenciam, positivamente, no grau de agregação entre indivíduos, na população de $U$. cordatus (Oliveira, 2005). No entanto, a resistência mecânica a penetração do sedimento e a densidade arbórea diminuem esse grau de agregação (Oliveira, 2005).

Abrunhosa et al. (2002) concluiram que larvas de $U$. cordatus necessitam de alimento para realizar a muda, diferente de muitas espécies de crustáceos, que completam um estágio (ou mesmo todo o desenvolvimento larval) sem buscar alimentos. Para esse autor, náuplios de Artemia não parecem ser 0 alimento adequado para as larvas de $U$. cordatus no $1^{\circ}$ estágio. Entretanto, a microalga Dunaliella sp., além de contribuir para a manutenção da qualidade da água em condições de cultivo, influencia positivamente na muda e na atividade dos indivíduos. Sem alimentação, apenas um pequeno percentual das larvas conseguiu atingir o estágio subseqüente de zoea II (Abrunhosa et al. (2002)).

$O$ alimento ingerido por $U$. cordatus é obtido durante a baixa-mar, nas proximidades das tocas (Nordhaus, 2003; Nordhaus e Wolff, 2007). Análises de conteúdo estomacal indicam que sua dieta é constituída por folhas de mangue $(61,2 \%)$, material vegetal não identificado e detritos $(28,0 \%)$, raízes $(4,9 \%)$, sedimento $(3,3 \%)$, casca de árvores $(2,5 \%)$ e material de origem animal, como crustáceos, poliquetos, insetos, bivalves e gastrópodes $(0,1 \%)$ (Nordhaus, 2003; Nordhaus e Wolff, 2007). Christofoletti (2005) corrobora com Nordhaus (2003), observando que as folhas corresponderam ao principal item na dieta desta espécie. A grande variedade de alimentos que faz parte da dieta de $U$. cordatus permite classificar a espécie como onívora (Branco, 1993).

A abertura de galerias de caranguejos é um traço da intensa atividade biogênica nos solos dos manguezais (Blankensteyn et al., 1997). Associado ao ciclo biogeoquímico no ecossistema estuarino, $U$. cordatus tem papel central na degradação de matéria orgânica através do consumo de resíduos vegetais e na retenção de carbono e nutrientes (Nordhaus et al., 2006). A degradação mediada pela atividade de caranguejo-uçá é 2,4 vezes mais rápida do que aquela que ocorre na superfície do solo (Schories et al., 2003; Silva, 2002; Dittmar e Lara, 2001; Middleton e Mckee, 2001; Corrêa Jr., 1998).

Como resultado de uma intensa atividade extrativista de captura, os estoques pesqueiros de caranguejo-uçá têm sofrido redução, podendo resultar no esgotamento deste recurso em escala econômica e em graves desequilíbrios ecológicos (Piou et al., 2007). Relato de catadores de caranguejo sobre a diminuição dos estoques naturais não são raros, como observado por Souto (2007), durante pesquisas realizadas com catadores do Distrito de Acupe, em Santo Amaro-BA.

Wolff et al., (2000) sugeriram a hipótese de que, como resultado da diminuição dessa população, haveria um aumento na quantidade de matéria orgânica não degradada em manguezais. Conseqüentemente, segundo esses autores, ocorreria uma elevação na quantidade de camarões no estuário, pelo aumento da oferta de alimento, e um efeito negativo sobre as populações de Uca pugnax (Smith, 1870) e seus predadores. Uca. pugnax é uma espécie detritívora, que utiliza como fonte de alimento os resíduos da alimentação de $U$. cordatus em processo de degradação microbiana. Contudo, até o momento, essas hipóteses permanecem não testadas. 


\section{BIOINDICADOR AMBIENTAL}

Ucides cordatus pode ser um importante bioindicador de qualidade ambiental, pois além de ser encontrado em grande parte do litoral brasileiro, demonstra sensibilidade a diversos poluentes (Santos, 2002). Toledo et al. (2007), ressalta a eficiência de $U$. cordatus como bioindicador de genotoxicidade em áreas de manguezal, propiciando a conservação e 0 biomonitoramento ambiental. Dentro dessa mesma proposta, Nudi et al.(2007) indicam $U$. cordatus como um excelente bioindicador da presença de óleo em manguezais.

O benzeno, químico largamente utilizado como solvente industrial, é uma fonte em potencial de contaminação de áreas de manguezais. A utilização de $U$. cordatus como bioindicador parece viável, pois uma breve exposição ao benzeno é capaz de causar mudanças metabólicas significativas, podendo comprometer processos vitais (Toledo, 1999; Santos, 2002).

A utilização de $U$. cordatus como bioindicador também pode ser realizada para avaliação da presença de poluentes contendo metais pesados (Corrêa Jr. et al., 2000; Harris e Santos, 2000). A ação de metais pesados no organismo de $U$. cordatus revelou sinais de comprometimento do sistema hormonal, como relatado por Corrêa Jr. et al. (2005).

Tavares et al. (1999) quantificaram as concentrações de DDT, DDE, DDD, $\mathrm{HCB}, \mathrm{HCH}$, Aldrin, Dieldrin e Endrin na Baía de Todos os Santos - BA (Brasil) em sedimento e bioindicadores (U. cordatus e três espécies de moluscos bivalves). Entre os resíduos pesquisados em moluscos e caranguejos, foram encontrados altos níveis de DDT.

Miguel et al. (2002) pesquisaram os efeitos da radiação U.V. sobre o sistema visual de $U$. cordatus, mais especificamente sobre os neurônios de primeira e segunda ordem presentes nos olhos. A partir desses estudos, concluiu-se que os órgãos da visão de $U$. cordatus apresentam alta sensibilidade à radiação U.V., sugerindo que alterações na camada de ozônio possam ocasionar lesões irreversíveis em indivíduos dessa espécie.

\section{IMPORTÂNCIA SOCIOECONÔMICA}

Dentre os recursos naturais extraídos de manguezais, a captura de caranguejo-uçá é considerada a atividade econômica mais importante conduzida em escala comercial no Brasil (Vieira et al., 2004; Saint-Paul, 2006). Wolff et al. (2000), Santos (2002) e Glaser e Diele (2004), corroborando com o descrito por Glaser (2003), enfatizam que U. cordatus é uma espécie de grande importância econômica, constituindo fonte de renda para parte da população com baixo poder aquisitivo da região Norte do Brasil.

Pesquisas quanto aos aspectos sócioeconômicos e a percepção ambiental dos catadores de caranguejo-uçá, desenvolvidas por Alves e Nishida (2003) e Alves et al. (2005), revelaram uma situação sócioeconômica aquém do esperado para a manutenção de uma boa qualidade de vida desses trabalhadores na região do estuário do Rio Mamanguape, Nordeste do Brasil. Botelho et al. (1999) verificaram que catadores de caranguejo-uçá do estuário dos rios Formoso (Rio Formoso) e llhetas (Tamandaré), no Estado de Pernambuco, capturaram cerca de 360 caranguejos/catador/semana.

Considerando que o valor médio de mercado do caranguejo-uçá nesta região é de US\$12,00/100 unidades, a captura de caranguejo contribui com cerca de US\$ $43,20 /$ catador/semana. Fiscarelli e Pinheiro (2002) descreveram 0 perfil sócioeconômico de catadores de caranguejo em Iguape/SP, como sendo com idade média de 16 a 58 anos, $88 \%$ do sexo masculino, não possuindo ensino fundamental completo e com uma renda mensal média de U\$160.00, superior 
àquela que caracteriza os $10 \%$ mais pobres da população brasileira. As mulheres trabalham no processamento do caranguejo, retirando a carne para a comercialização. $O$ trabalho feminino é pouco valorizado, embora contribua com a renda familiar, e tem baixa remuneração (Magalhães et al., 2007).

Estimativas de captura desta espécie no litoral brasileiro são muito heterogêneas, variando de $12 \mathrm{t}$ a quase $5000 \mathrm{t}$, como observado na tabela 1.

Glaser (2003), após colher informações de 13000 habitantes de 21 comunidades rurais do Estuário de Caeté, norte do Brasil, verificou que o caranguejouçá é a espécie mais importante economicamente para a região, visto que se mostrou ser a principal fonte de renda para $38 \%$ dos catadores pesquisados. Nordi (1994) constatou grande relevância na captura de U. cordatus para a Região de Várzea Nova, Paraíba, Brasil, no que se refere principalmente à produção de proteína animal para consumo humano.

Tabela 1 - Quantidade, em toneladas, de caranguejo-uçá capturado no litoral brasileiro.

\begin{tabular}{llll}
\hline Local & Data & Ton/ano & $\begin{array}{l}\text { Total } \\
\text { (Ton) }\end{array}$ \\
\hline Caeté-Pará $^{1}$ & 1997 & 3300 & 3300 \\
Maranhão e Pará $^{2}$ & 1998 a 1999 & 4850 & 9700 \\
Piauí $^{3}$ & 1980 a 1990 & 76 & 760 \\
Regiões Sudeste e Sul $^{2}$ & 1998 & 632 & 632 \\
Rio Grande do Norte $^{3}$ & 1980 a 1990 & 12 & 118 \\
Rio Grande do Norte $^{3}$ & 1996 & 23 & 23 \\
Sergipe $^{3}$ & 1980 a 1990 & 32 & 288 \\
\hline
\end{tabular}

Fontes: ${ }^{1}$ WOLFF et al.(2000); ${ }^{2}$ IBAMA (2002); ${ }^{3}$ IVO e GESTEIRA (1999).

A exploração comercial de $U$. cordatus em Gargaú/RJ, é realizada durante todo ano e a "redinha", armadilha de utilização proibida, é o principal método de captura. De modo geral, o tipo de captura praticada pelos pescadores exclui fêmeas ovígeras e espécimes com largura de carapaça (LC) inferior a $6,0 \mathrm{~cm}$, uma vez que a demanda é por exemplares maiores (Passos e Beneditto, 2005). O mesmo ocorre no estuário de Caetés, onde são coletados, preferencialmente, machos grandes, com LC média de $6,5 \mathrm{~cm}$ (Diele et al., 2005).

$O$ uso indiscriminado da redinha, aliado ao aumento do número de catadores, maximiza a pressão de coleta, ao mesmo tempo em que promove a redução do tamanho médio do caranguejouçá. Esta redução leva a uma prevalência de caranguejos adultos com menor tamanho médio, o que promove alterações na estrutura populacional que comprometem os elos manguezalcaranguejo e caranguejo-homem (Jankowsky et al, 2006).

Analisando a viabilidade técnicoeconômica de cultivos de $U$. cordatus no litoral paranaense, Ostrensky et al. (1995) verificaram que os cultivos, em substituição à atividade extrativista, seriam a forma mais sustentável de viabilizar a estruturação de empresas processadoras de caranguejo, além de minimizar possíveis impactos decorrentes de uma exploração indiscriminada dos estoques naturais. Entretanto, esses autores concluem que, apesar do caranguejo-uçá apresentar uma boa adaptação ao cativeiro, o período estimado para que a espécie atinja 0 tamanho comercial é superior a 6,3 anos, o que inviabilizaria economicamente qualquer tentativa de cultivo em escala comercial.

\section{ALIMENTAÇÃO HUMANA}

Estudos etnobiológicos da interação entre catadores de caranguejo na comunidade pesqueira do Estado da Bahia, Brasil, demonstraram que, assim como Cardisoma guanhumi (Latreille, 1825) e Ocypode quadrata (Fabricius, 1787), o caranguejo-uçá é amplamente consumido e tradicionalmente utilizado como recurso medicinal para o tratamento de doenças localmente diagnosticadas (Costa Neto e Lima, 2000). 
A carne de $U$. cordatus, é considerada um alimento rico em proteínas e minerais, principalmente zinco, com baixos teores lipídicos e calóricos (Pedrosa e Cozzolino, 2001). Blankensteyn et al. (1997) verificaram que a carne de $U$. cordatus provenientes da llha das Peças PR apresentava cerca de $73,4 \%$ de teores protéicos em relação ao seu peso seco, praticamente o mesmo valor quantificado em exemplares de Guaraqueçaba, naquele caso $73,63 \%$.

Fiscarelli (2004), por sua vez, encontrou uma taxa protéica de $16 \%$ e uma reduzida taxa de lipídios $(0,2 \%)$, que somados aos demais componentes, caracteriza uma carne de excelente valor nutritivo.

Pesquisando sobre patógenos relacionados à ocorrência de Doenças Transmitidas por Alimentos, Theophilo (1992) isolou em amostras de carne crua e cozida de $U$. cordatus comercializadas em Fortaleza, Ceará, 65 cepas de Vibrio parahaemoliticus (Sakazaki et al., 1963). Vieira et al. (2004) pesquisaram a presença de Vibrio spp. e de Salmonella spp. (Lignieres, 1900) em adultos de U. cordatus comercializados vivos também em Fortaleza. A análise microbiológica da carne destes caranguejos revelou a presença dos sorovares de Salmonella senftenberg e Salmonella poona e um Número Mais Provável (NMP) de Vibrio spp. [ $V$. alginolyticus (Miyamoto et al,. 1961) e V. parahaemolyticus] variando entre 110/g e 110000/g. Bactérias pertencentes à Enterobacteriaceae e Pseudomonaceae também foram detectadas nas amostras analisadas, as quais foram identificadas como: Escherichia coli (Migula, 1895), Klebsiella pneumoniae (Schroeter,1886), Enterobacter cloacae (Jordan, 1890), Pantoea agglomerans (Ewing e Fife, 1972) e Pseudomonas aeruginosa (Schroeter, 1872). No entanto, conforme a Resolução da ANVISA (Agência Nacional de Vigilância Sanitária) - RDC n912, de 02 de janeiro de
2001, que se aplica aos alimentos destinados ao consumo humano, apenas Staphylococcus coagulase positiva - do qual faz parte Staphylococcus aureus (Rosenbach, 1884) -, Salmonella sp. e coliformes termotolerantes (coliformes a $45^{\circ} \mathrm{C}$ ou coliformes fecais) têm a análise exigida, não sendo definidos valores de referência para demais microorganismos.

\section{DOENÇA DO CARANGUEJO LETÁRGICO (DCL)}

Responsável por elevadas taxas de mortalidade de $U$. cordatus na região Nordeste do Brasil, a Doença do Caranguejo Letárgico tem como agente causal um fungo anamorfo Ascomycota, identificado como "Exophiala-like" (Boeger et al., 2007). Embora os estudos tenham se iniciado por volta de 1997, ainda pouco se conhece quanto aos mecanismos de transmissão da doença (Boeger et al., 2005).

A histopatologia da DCL indica que muitos tecidos são afetados, tais como as brânquias, o coração, a epiderme, o hepatopâncreas, o sistema nervoso e o tecido conjuntivo. Gônadas, tecido muscular e sistema digestório são pouco afetados pelo fungo (Boeger et al., 2007).

O diagnóstico dessa enfermidade é realizado através de exame clínico, quando os sinais de elevada ataxia e apatia estão evidentes, por pesquisa histológica sob microscopia óptica e eletrônica, e de "Polymerase Chain Reaction" (PCR) com iniciadores específicos (Boeger et al., 2005).

\section{CONSIDERAÇÕES FINAIS}

Em função da sua grande importância ambiental e socioeconômica, a espécie $U$. cordatus é estudada sob os mais diversos enfoques, como demonstrado neste trabalho. Porém, em virtude do intenso esforço de pesca a que a espécie vem sendo submetida ao longo de 
quase todo o litoral brasileiro, à descaracterização de seus habitats naturais e ao surgimento de doenças emergentes, como a DCL, que tem provocado extensa mortalidade em manguezais do nordeste brasileiro, pesquisas que aprofundem o conhecimento de sua bioecologia, técnicas de manejo e gerenciamento dos seus estoques pesqueiros passarão a ser fundamentais para a preservação da espécie.

\section{REFERÊNCIAS}

ABRUNHOSA, F. A. ; SILVA NETO, A. A.; MELO, M. A.; CARVALHO, L. O. Importância da alimentação e do alimento no primeiro estágio larval de Ucides cordatus cordatus (Linnaeus, 1763) (Decapoda: Ocypodidae), Revista Ciência Agronômica, v. 33, n. 2, p. 5 - 12. 2002.

ALLODI, S.; TAFFAREL, M. Electron microscopy of glial cells of the central nervous system in the crab Ucides cordatus. Brazilian Journal of Medical and Biological Research, v. 32, p. 327-331. 1999.

ALLODI, S.; FARINA, M.; CORRÊA Jr., J. D. Cytoarchitectural features of Ucides cordatus (Crustacea Decapoda) hepatopancreas: structure and elemental composition of electron-dense granules. Tissue \& Cell, v. 34, n. 5, p. 315-325. 2002.

ALVES, M. I. M. Sobre a reprodução do caranguejouçá, Ucides cordatus (Linnaeus), em mangues do Estado do Ceará (Brasil). Arquivos de Ciências do Mar, v. 15, n. 2, p. 85-91. 1975.

ALVES, R. R. N.; NISHIDA, A. K. Socio-economical aspects and environmental perception of 'Caranguejo-uçá', U. cordatus (L. 1763) (Decapoda, Brachyura) gatherers in the Mamanguape river estuary, northeast Brazil. Interciência, v. 28, n. 1, p. 36-43. 2003.

ALVES, R. R. N.; NISHIDA, A. K.; HERNÁNDEZ, M. I. M. Environmental perception of gatherers of the crab 'caranguejo-uçá' (Ucides cordatus, Decapoda, Brachyura) affecting their collection attitudes. Journal of Ethnobiology and Ethnomedicine, v. 1, p: 10. 2005.

ALVES, R. R. N.; NISHIDA, A. K. A ecdise do caranguejo-uçá, Ucides cordatus L. (Decapoda, Brachyura) na visão dos caranguejeiros. Interciência, v.27 n.3. 2002.

BECKER, A. Utilização de organismos-alimento na larvicultura do caranguejo-uçá, Ucides cordatus (Linnaeus, 1763) (CRUSTACEA, BRACHYURA, OCYPODIDAE). Curitiba, 2008. 53. Curitiba, 2008. 53 p. Dissertação (Mestrado em Ciências Veterinárias) - Setor de Ciências Agrárias, Universidade Federal do Paraná.

BLANKENSTEYN, A.; CUNHA FILHO, D.; FREIRE, A. S. Distribuição, estoques pesqueiros e conteúdo protéico do caranguejo do mangue Ucides cordatus (L. 1763) (Brachyura: Ocypodidae) nos manguezais da Baía das Laranjeiras e adjacências, Paraná, Brasil. Arquivos de Biologia e Tecnologia, v. 40, n. 2, p. 331-349. 1997.

BOEGER, W. A.; PIE, M. R.; OSTRENSKY, A.; PATELLA, L. Lethargic crab disease: multidisciplinary evidence supports a mycotic etiology. Memórias do Instituto Oswaldo Cruz, v. 100, n. 2, p. 161-167. 2005.

BOEGER, W. A.;. PIE, M. R.; VICENTE,V.; OSTRENSKY, A.; HUNGRIA, D.; CASTILHO, G. G. Histopathology of the mangrove land crab, Ucides cordatus (Ocypodidae), affected by Lethargic Crab Disease: clues to understanding the disease. Diseases of Aquatic Organisms, 78:73-81. 2007.

BOTELHO, E. R. O.; DIAS, A. F.; IVO, C. T. C. Study on the biology of $U$. cordatus, catched in the estuaries of rivers Formoso and llhetas, Pernambuco State, Brazil. Boletim técnico científico do Centro de Pesquisa e Gestão de Recursos Pesqueiros do Litoral Nordeste, v. 7, n. 1, p. 117-145. 1999.

BRASIL. Agência Nacional de Vigilância Sanitária (ANVISA). Resolução - RDC n12, de 02 de Janeiro de 2001, Regulamento Técnico sobre padrões microbiológicos para alimentos. 2001.

BRANCO, J. O. Aspectos bioecológicos do caranguejo Ucides cordatus (Linnaeus, 1763) (Crustacea, Decapoda) do manguezal do Itacorubi, Santa Catarina, Brasil. Arquivos de Biologia e Tecnologia, v. 36, n. 1, p. 133-148. 1993.

BRIGHT, D. B.; HOGUE, C. L. A synopsis of the burrowing land crabs of the world and list of their arthropod symbionts and burrow associates, Los Angeles - USA: Natural History Museum, $n^{\circ} 220,1972$.

CASTILHO, G. G. Aspectos reprodutivos do caranguejo-uçá, Ucides cordatus (L.) (Crustacea, Brachyura, Ocypodidae), na Baía de Antonina, Paraná, Brasil. Curitiba, 2006. 119 p. Dissertação (Mestrado em Ciências Veterinária) - Setor de Ciências Agrárias, Universidade Federal do Paraná.

CASTILHO, G. G.; OSTRENSKY, A.; PIE, M.; BOEGER, W. Morphology and histology of the male reproductive system of the mangrove land crab Ucides cordatus (L.) (Crustacea, Brachyura, 
Ocypodidae). Acta Zoologica (Stockholm), 89:157-161. 2008.

CHRISTOFOLETTI, R. A. Ecologia trófica do caranguejo-uçá, Ucides cordatus (Linnaeus, 1763) (Crustacea, Ocypodidae) e o fluxo de nutrientes em bosques de mangue, na região de Iguape (SP). São Paulo, 2005. 127f. Tese (doutorado) - Universidade Estadual Paulista, Faculdade de Ciências Agrárias e Veterinárias.

CORRÊA Jr., J. D. Ocorrência, composição e mapeamento elementar de minerais amorfos encontrados em células hepatopancreáticas do caranguejo Ucides cordatus (CrustaceaDecapoda), Rio de Janeiro, 1998. 78 p. Dissertação (Mestrado em Ciências Morfológicas), Universidade Federal do Rio de Janeiro.

CORRÊA Jr., J. D.; ALLODI, S.; AMADO-FILHO, G. M.; FARINA, M. Zinc accumulation in phosphate granules of Ucides cordatus hepatopâncreas. Brazilian Journal of Medical and Biological Research, v. 33, p. 217-221. 2000.

CORRÊA Jr., J. D.; ALLODI, S.; FARINA, M. Enzymatic, analytical and structural aspects of electron-dense granules in cells of Ucides cordatus (Crustacea, Decapoda) Hepatopâncreas. Cell Tissue Research, v. 311, p. 107-116. 2003.

CORRÊA Jr., J. D.; SILVA, M. R.; SILVA, A. C. B.; LIMAD, S. M. A.; MALME, O.; ALLODI, S. Tissue distribution, subcellular localization and endocrine disruption patterns induced by $\mathrm{Cr}$ and $\mathrm{Mn}$ in the crab Ucides cordatus. Aquatic Toxicology, v. 73, p. 139-154. 2005.

COSTA, R. S. Bioecologia do Caranguejo-uçá, Ucides cordatus (Linnaeus, 1763) - Crustáceo, Decápode - no nordeste brasileiro. Boletim Cearense de Agronomia, v. 20, p. 1-74. 1979.

COSTA NETO, E. M.; LIMA, K. L. G. Contribution to the study of interaction between fishermen and crab (Crustacea, Decapoda, Brachyura): ethnobiological considerations in a fishing community from the State of Bahia, Brazil. Actualidades Biologicas, Medellin, v. 22, n. 73, p. 195-202. 2000.

COSTA, P. V. Caranguejo - Predação de larvas de caranguejo (infraordem Brachyura) por peixes no rio dos Pinheiros. Curitiba, 2006. 73 p. Dissertação (Mestrado em Ciências Veterinária) Setor de Ciências Agrárias, Universidade Federal do Paraná.

DALABONA, G. Reprodução e Análise Biométrica do Caranguejo-uçá Ucides cordatus nas Ilhas do Pavoçá e das Peças, Paraná, Brasil. Curitiba, 2001. 36 p. Dissertação (Mestrado em Ciências Biológicas, Área de Zoologia) - Setor de Ciências Biológicas, Universidade Federal do Paraná.
DALABONA, G.; SILVA, J. L.; PINHEIRO, M. A. A. Size at morphological maturity of Ucides cordatus (Linnaeus, 1763) (Brachyura, Ocypodidae) in the Laranjeiras Bay, Southern Brazil. Brazilian Archives of Biology and Technology, v. 48, n. 1, p. 139-145. 2005.

DIELE, K. Life history and population structure of the exploited mangrove crab $U$. cordatus (L.) (Decapoda: Brachyura) in the Caeté estuary, North Brazil. Bremen, 2000. 103f. Tese (Doutorado na área de especialidade 2 - Biologia/Química) Zentrum für Marine Tropenökologie, Universität Bremen.

DIELE, K.; KOCH, V.; SAINT-PAUL, U. Population structure, catch composition and CPUE of the artisanally harvested mangrove crab Ucides cordatus (Ocypodidae) in the Caeté estuary, North Brazil: Indications for overfishing? Aquatic Living Resources, v. 18, p. 169-178. 2005.

DIELE, K.; SMITH, D. J. B. Salinity tolerance of northern Brazilian mangrove crab larvae, Ucides cordatus (Ocypodidae): Necessity for larval export? Estuarine, Coastal and Shelf Science, v. 68, p. 600-608. 2006.

DIELE, K.; SMITH, D.J.B. Effects of substrata and conspecific odour on the metamorphosis of mangrove crab megalopae, Ucides cordatus (Ocypodidae) Journal of Experimental Marine Biology and Ecology, v. 348, n.1-2, p.174-182. 2007.

DITTMAR, T.; LARA, R. J. Molecular evidence for lignin degradation in sulfate-reducing mangrove sediments (Amazônia, Brazil). Geochimica et Cosmochimica Acta, v. 65, n. 9, p.1417-1428. 2001.

FISCARELLI, A. G. Rendimento, análise químicobromatológica da carne e fator de condição do caranguejo-uçá Ucides cordatus (Linnaeus, 1763) (Crustacea, Brachyura, Ocypodidae). São Paulo, 2004, 94 p. Dissertação (Mestrado em Zootecnia - Produção Animal), Faculdade de Ciências Agrárias e Veterinárias - Unesp, Campus de Jaboticabal.

FISCARELLI, A. G.; PINHEIRO, M. Perfil sócioeconômico e conhecimento entnobiológico do catador de caranguejo-uçá, Ucides cordatus (Linnaeus, 1763), nos manguezais de Iguape (24\%1'S), SP, Brasil. Actual Biological, v.24, n. 77, p. 129-142. 2002.

FREIRE, A. S. Dispersão larval do Caranguejo do mangue Ucides cordatus (L.1763) em manguezais da Baía de Paranaguá, Paraná. São Paulo, 1998. 71pf. Tese (Doutorado em Oceanografia Biológica), Universidade de São Paulo. 
GARCIA DE GERALDES, M; BONNELLI DE CALVENTI, I. Experimental surveys on the maintenance in of Ucides cordatus. Ciencia Interamericana, v. 23, n. 1-4, p. 41-53. 1983.

GLASER, M. Interrelations between mangrove ecosystem, local economy and social sustainability in Caeté Estuary, North Brazil. Wetlands Ecology and Management, v. 11, p. 265-272. 2003.

GLASER, M.; DIELE, K. Asymmetric outcomes: assessing central aspects of the biological, economic and social sustainability of a mangrove crab fishery, Ucides cordatus (Ocypodidae), in North Brazil. Ecological Economics, v. 49, p. 361-373. 2004.

GÓES, P.; SAMPAIO, F. D. F; CARMO, T. M. S.; TOSO, G. C; LEAL, M. S. Comportamento e período reprodutivo do caranguejo do mangue Ucides cordatus. Anais do V Simpósio de Ecossistemas Brasileiros: Conservação, Universidade Federal do Espírito Santo, v. 2, p. 335-345. 2000.

HARRIS, R. R.; SANTOS, M. C. F. Sodium uptake and transport $(\mathrm{Na}++\mathrm{K}+)$ ATPase changes following $\mathrm{Na}+$ depletion and low salinity acclimation in the mangrove crab Ucides cordatus (L.). Comparative Biochemistry and Physiology Part A: Physiology, v. 105, n. 1, p. 35-42. 1993.

HARRIS, R. R.; SANTOS, M. C. F. Heavy metal contamination and physiological variability in the Brazilian mangrove crabs Ucides cordatus and Callinectes danae (Crustacea: Decapoda). Marine Biology, v. 137, p. 691-703. 2000.

HARRIS, R. R.; SANTOS, M. C. F. Ionoregulatory and urinary responses to emersion in the mangrove crab Ucides cordatus and the intertidal crab Carcinus maenas. Journal of Comparative Physiology B: Biochemical, Systemic, and Environmental Physiology, v. 163, n. 1, p. 18-27. 2004.

HATTORI, G. Y. Biologia populacional do caranguejo de mangue Ucides cordatus (Linnaeus, 1763) (Crustacea, Brachyara, Ocypodidae) em Iguape (SP). São Paulo, 2002. 82 p. Dissertação (Mestrado em Zootecnia, Área de Produção Animal), Universidade Estadual Paulista Júlio de Mesquita Filho - Jaboticabal.

HATTORI, G. Y. Densidade populacional do caranguejo-uçá, Ucides cordatus (Linnaeus, 1763) (Crustacea, Brachyura, Ocypodidae), na Região de Iguape (SP). São Paulo, 2006. $146 f$. Tese (Doutorado em Zootecnia - Produção Animal), Faculdade de Ciências Agrárias e Veterinárias UNESP, Campus de Jaboticabal.

HATTORI, G. Y.; PINHEIRO, M. Fertilidade do caranguejo de mangue Ucides cordatus (Linnaeus) (Crustacea, Brachyura, Ocypodidae), em Iguape
(São Paulo, Brasil). Revista Brasileira de Zoologia, v. 20, n. 2, p. 309-313. 2003a.

HATTORI, G. Y.; PINHEIRO, M. Embryology of the mangrove crab Ucides cordatus (Brachyura: Ocypodidae). Journal of Crustacean Biology, v. 23, n. 3, p. 729-737. 2003b.

IBAMA - INSTITUTO BRASILEIRO DO MEIO AMBIENTE E DOS RECURSOS NATURAIS RENOVÁVEIS. O Estado dos Recursos Pesqueiros: Pesca Extrativa e Aqüicultura, in: Geo Brasil Perspectivas do Meio Ambiente no Brasil. Brasília: Edições IBAMA, p.132-147. 2002.

IVO, C. T. C.; GESTEIRA, T. C. V. Synopsis of the observations on the bioecology and fishery of the mangrove crab $U$. cordatus (Linnaeus, 1763), caught in estuaries in Brazil. Boletim técnico científico do Centro de Pesquisa e Gestão de Recursos Pesqueiros do Litoral Nordeste, v. 7, n. 1, p. 9-52. 1999.

JANKOWSKY, M.; PIRES, J. S. R.; NORDI, N. Contribuição ao manejo participativo do caranguejouçá, Ucides cordatus (L., 1763), em Cananéia - SP. Boletim do Instituto de Pesca, v. 32, n. 2, p. 221228, 2006.

LUCU, C.; TOWLE, D. W. Na+ + K+ - ATPase in gills of aquatic Crustacea. Comparative Biochemistry and Physiology - Part A, v. 135, p. 195-214. 2003.

MAGALHÃES, A.; COSTA, R. M.; SILVA, R.; PEREIRA, L. C. C. The role of women in the mangrove crab (Ucides cordatus, Ocypodidae) production process in North Brazil (Amazon region, Pará). Ecological Economics, v. 6, p. 559 - 565. 2007.

MARTELO, M. J.; ZANDERS, I. P. Influence of temperature on ionic regulation in blood and urine of the mangrove crab Ucides cordatus (L.). Comparative Biochemistry and Physiology Part A: Physiology, v. 78, n. 2, p. 255-258. 1984.

MARTINEZ, C. B. R.; ALVARES, E. P.; HARRIS, R. R.; SANTOS, M. C. F. A morphological study on posterior gills of the mangrove crab Ucides cordatus. Tissue \& Cell, v. 31, n. 3, p. 380-389. 1999.

MARTINEZ, C. B. R.; HARRIS, R.R.; SANTOS, M.C.F. Transepithelial potential differences and sodium fluxes in isolated perfused gills of the mangrove crab Ucides cordatus. Comparative Biochemistry and Physiology - Part A, v. 120, p. 227-236. 1998.

MELO, G. A. S. Manual de identificação dos Brachyura (caranguejos e siris) do litoral brasileiro. São Paulo: Editora Plêiade, 1996.

MIDDLETON, B. A.; MCKEE, K. L. Degradation of mangrove tissues and implications for peat 
formation in Belizean island forests. Journal of Ecology, v. 89, p. 818-828. 2001.

MIGUEL, N. C. O.; MEYER-ROCHOWC, V. B.; ALLODIA, S. Ultrastructural study of first and second order neurons in the visual system of the crab Ucides cordatus following exposure to ultraviolet radiation. Micron, v. 33, p. 627-637. 2002.

NAKAMURA, I. T. Sobre a fenologia de Ucides cordatus (Linnaeus, 1763), (Crustacea, Brachyura), da Baía de Paranaguá. Curitiba, 1979. 71 p. Dissertação (Mestrado em Ciências Biológicas, área de Zoologia) - Setor de Ciências Biológicas, Universidade Federal do Paraná.

NORDI, N. A produção dos catadores de caranguejo-uçá (Ucides cordatus) na região de Várzea Nova, Paraíba, Brasil. Revista Nordestina de Biologia, v. 9, n. 1, p. 71-77. 1994.

NORDHAUS, I. Feeding ecology of the semiterrestrial crab $U$. cordatus (Decapoda: Brachyura) in a mangrove forest in northern Brazil. Bremen, 2003. 217f. Tese (Doutorado em Ciências Naturais) - Zentrum für Marine Tropenökologie, Universität Bremen.

NORDHAUS, I.; WOLFF, M.; DIELE, K. Litter processing and population food intake of the mangrove crab Ucides cordatus in a high intertidal forest in northern Brazil. Estuarine, Coastal and Shelf Science, v. 67, p. 239-250. 2006.

NORDHAUS, I.; WOLFF, M. Feeding ecology of the mangrove crab Ucides cordatus (Ocypodidae): food choice, food quality and assimilation efficiency. Marine Biology, v. 151, n. 5, 07p. 1665-1681. 2007.

NUDI, A. H.; WAGENER, A. L. R.; FRANCIONI, E.; SCOFIELD, A. L., SETTE, C.; VEIGA, A. Validation of Ucides cordatus as a bioindicator of oil contamination and bioavailability in mangroves by evaluating sediment and crab $\mathrm{PAH}$ records. Environment International, v. 33, p. 315-327. 2007.

OLIVEIRA, D. A. F. Distribuição espacial do caranguejo-uçá, Ucides cordatus (Linnaeus, 1763) (Crustacea, Brachyura, Ocypodidae), São Vicente-SP, 2005, 57f. Trabalho de Conclusão de Curso apresentado à Universidade Estadual Paulista (UNESP), Campus do Litoral Paulista Unidade São Vicente, como parte dos requisitos para obtenção do Bacharelado em Ciências Biológicas, com Habilitação em Biologia Marinha.

OLIVEIRA-NETO, J. F.; BOEGER, W. A.; PIE, M. R.; OSTRENSKY, A.; HUNGRIA, D. B. Genetic structure of populations of the mangrove crab Ucides cordatus Decapoda: Ocypodidae) at local and regional scales. Hydrobiologia, v. 583, p. 6976. 2007a.
OLIVEIRA-NETO, J.F.; PIE, M.R. ; BOEGER, W. A.; OSTRENSKY, A.; BAGGIO, R.A. Population genetics and evolutionary demography of Ucides cordatus (Decapoda: Ocypodidae). Marine Ecology, v. 28, n. 4, p. 460-469. 2007b.

OSTRENSKY, A.; STERNHAIN, U. S.; BRUN, E.; WEGBECHER, F. X.; PESTANA, D. Análise da viabilidade técnico-econômica dos cultivos do caranguejo-uçá Ucides cordatus (Linnaeus, 1763) no litoral paranaense. Arquivos de Biologia e Tecnologia, v. 38, n. 3, p. 939-947. 1995.

PASSOS, C. A.; BENEDITTO, A. P. M. Captura comercial do caranguejo-uçá, Ucides cordatus (L., 1763), no Manguezal de Gargaú, RJ. Biotemas, v. 18, n. 1, p. $223-231.2005$.

PEDROSA, L. F. C.; COZZOLINO, S. M. F. Composição centesimal e de minerais de mariscos crus e cozidos da cidade de Natal/RN. Ciência e Tecnologia de Alimentos, v. 21, n. 2, p. 154-157. 2001.

PINHEIRO, M.; BAVELONI, M. D.; TERCEIRO, O. S. L. Fecundity of the mangrove crab Ucides cordatus (Linnaeus, 1763) (Brachyura, Ocypodidae). Invertebrate Reproduction and Development, v. 43, n. 1, p. 19-26. 2003.

PINHEIRO, M. A. A.; FISCARELLI, A. G.; HATTORI, G. Y. Biologia reprodutiva do caranguejo-uçá, Ucides cordatus (Brachyura: Ocypodidae), em Iguape, SP. Anais do I Congresso Brasileiro sobre Crustáceos, RE - 187, p. 151. 2000.

PINHEIRO, M. A. A.; FISCARELLI, A. G. Manual de apoio à fiscalização do caranguejo-uçá (Ucides cordatus). Itajaí, Santa Catarina: Centro de Pesquisa e Gestão de Recursos Pesqueiros do Litoral Sudeste e Sul - CEPSUL. 2001.

PINHEIRO, M. A. A.; FISCARELLI, A. G.; HATTORI, G. Y. Growth of the mangrove crab Ucides cordatus (Brachyura, Ocypodidae). Journal of Crustacean Biology, v. 25, n. 2, p. 293-301. 2005.

PINHEIRO, M. A. A.; HATTORI, G. Y. Embryology of the mangrove crab Ucides cordatus (Brachyura: Ocypodidae). Journal of Crustacean Biology, v. 23, n. 3, p. 729-737. 2003.

PINHEIRO, M. A. A.; HATTORI, G. Y. Relative Growth of the Mangrove Crab Ucides cordatus (Linnaeus, 1763) (Crustacea, Brachyura, Ocypodidae) at Iguape, São Paulo, Brazil. Brazilian Archives of Biology and Technology - an International Journal, v.49, n. 5, p. 813-823. 2006.

PIOU, C.; BERGER, U.; HILDENBRANDT, H.; GRIMM, V.; DIELE, K.; D'LIMA, C. Simulating cryptic movements of a mangrove crab: Recovery phenomena after small scale fishery. Ecological Modelling, v. 205, n. 1, p.110-122. 2007. 
RODRIGUES, M. D. Desenvolvimento pósembrionário de Ucides cordatus (Linnaeus, 1763) (Crustácea, Decapoda, Gecarcinidae). São Paulo. 1982. 101 p. Dissertação, Universidade Estadual Paulista Júlio de Mesquita Filho.

RODRIGUES, M. D.; HEBLING, N. J. U. cordatus (Linnaeus, 1763) (Crustacea, Decapoda). Complete larval development under laboratory conditions and its systematic position. Revista Brasileira de Zoologia, v. 6, n. 1, p.147-166. 1989.

SAINT-PAUL, U. Interrelations among Mangroves, the Local Economy and Social Sustainability: a Review from a Case Study in North Brazil, in.: Environment and Livelihoods in Tropical Coastal Zones, eds HOANH, C.T.; TUONG, T.P.; GOWING, J.W.; HARDY, B., p. 154-162. 2006.

SANT'ANNA, B. S. Biologia reprodutiva do caranguejo-uçá, Ucides cordatus (Linnaeus, 1763), em Iguape, SP, Brasil. São Paulo, 2006. 64 p. Dissertação (Mestrado em Aqüicultura e Pesca), Instituto de Pesca.

SANT'ANNA, B. S.; PINHEIRO, M.; MATAQUEIRO, M.; ZARA, F. J. Spermathecae of the mangrove crab Ucides cordatus: a histological and histochemical view. Journal of Marine Biological Association U. K., v. 87, p. 903-911. 2007.

SANTOS, M. do C. F. Regulação osmótica e iônica no caranguejo de mangue Ucides cordatus (Linnaeus, 1763). Simpósio sobre ecossistemas da costa sul e sudeste brasileira - síntese dos conhecimentos, Cananéia, São Paulo: ACIEP, v. 2, p.149. 1987.

SANTOS, M. C. F. Drinking and osmoregulation in the mangrove crab Ucides cordatus following exposure to benzene. Comparative Biochemistry and Physiology - Part A, v. 133, p. 29 -42. 2002.

SANTOS, M. C. F.; SALOMÃO, L. C. Hemolymph osmotic and ionic concentrations in the gecarcinid crab Ucides cordatus. Comparative Biochemistry and Physiology Part A: Physiology, v. 81, n. 3, p. 581-583. 1985a.

SANTOS, M. C. F.; SALOMÃO, L. C. Osmotic and cationic urine concentrations/blood concentrations ratios in hyporegulating Ucides cordatus. Comparative Biochemistry and Physiology Part A: Physiology, v. 81, n. 4, p.895-898. 1985b.

SCHORIES, D.; BARLETTA-BERGAN, A.; BARLETTA, M.; KRUMME, U.; MEHLIG, U.; RADEMAKER, $V$. The keystone role of leafremoving crabs in mangrove forests of North Brazil. Wetlands Ecology and Management, v. 11, p. 243-255. 2003.

SCHMIDT, A. J.; ARAÚJO, S. M. B.; SOUZA, E. P.; MAY, M.; OLIVEIRA, M. A.; TARARAM, A. S. O papel dos apicuns na dinâmica populacional do caranguejo-uçá (Ucides cordatus cordatus) em manguezais de Canavieiras - BA. Anais do II Congresso Brasileiro de Oceanografia, Vitória ES. 2005.

SILVA, U. A. T. Cultivos experimentais de caranguejo-uçá, Ucides cordatus (Linnaeus, 1673). Curitiba, 2002. 89 p. Dissertação (Mestrado em Ciências Veterinárias), Universidade Federal do Paraná.

SILVA, U. A. T. Recuperação populacional de caranguejo-uçá, Ucides cordatus, através da liberação de formas imaturas em áreas antropicamente pressionadas. Curitiba, 2007. 174 p. Tese (Doutorado em Ciências - Zoologia), Universidade Federal do Paraná.

SOUTO, F. J. B. Uma abordagem etnoecológica da pesca do caranguejo, Ucides cordatus, Linnaeus, 1763 (Decapoda: Brachyura), no manguezal do Distrito de Acupe (Santo Amaro-BA). Biotemas, v. 20, n. 1, p. 69-80. 2007.

SPIVAK, E. D. Cangrejos estuariales del Atlántico sudoccidental (2541 $\subseteq$ ) (Crustacea: Decapoda: Brachyura). Investigaciones Marinas, v. 25, p. 105-120. 1997.

TAVARES, T.M.; BERETTA, M.; COSTA, M.C. Ratio of DDT/DDE in The All Saints Bay, Brazil and its use in environmental management. Chemosphere, v. 38, n. 6, pp. 1445-1452. 1999.

THEOPHILO, G. N. D. Isolamento de Vibrio parahaemoliticus em caranguejos comercializados em Fortaleza, CE. Ceará, 1992.122 p. Dissertação (Mestrado em Tecnologia de Alimentos), Universidade Federal do Ceará.

TOLEDO, A. C. C. Efeito do Benzeno e da mudança de salinidade no consumo de oxigênio e amônia excretada no caranguejo de mangue Ucides cordatus. São Paulo, 1999. 127 p. Dissertação (Mestrado em Ciências, Área de Fisiologia Geral), Universidade de São Paulo.

TOlEDO, T.R.; TORRES, R.A.; PINHEIRO, M.A.A. Avaliação do impacto genotóxico em Ucides cordatus (Linnaeus, 1763) (Crustacea, Brachyura, Ocypodidae) em sistemas de manguezais do sudeste do Brasil. XII Congresso LatinoAmericano de Ciências do Mar - XII COLACMAR, Florianópolis. 2007.

TURKIN, M. Q. A.; SAWAYA, M. I.; SANTOS, M. C. F.; VEIGA, L. V.; MANTERO, F.; OPOCHER, G. Atrial Natriuretic Peptide (ANP) increases in the mangrove crab Ucides cordatus when exposed to increased environmental salinity. Comparative Biochemistry and Physiology Part A: Physiology, v. 101, n. 4, p. 803-806. 1992. 
VENTURA, R. Caranguejo - Canibalismo e assentamento de formas jovens de caranguejouçá, Ucides cordatus (L.) (Crustacea, Brachyura, Ocypodidae), em condições de laboratório. Curitiba, 2006. 41p. Dissertação (Mestrado em Ciências Veterinárias), Universidade Federal do Paraná.

VENTURA, R. ; SILVA, U. A.; PERBICHE-NEVES, G. ; OSTRENSKY, A. ; BOEGER, W. A.; PIE, M. R. Duration of the pre-settlement period of the mangrove crab Ucides cordatus (Decapoda: Ocypodidae) under laboratory conditions. Brazilian Archives of Biology and Technology, no prelo, 2008.

VENTURA, R. ; SILVA, U.A. ; PERBICHE-NEVES, G. ; OSTRENSKY, A. ; BOEGER, W. A.; PIE, M.R. Larval cannibalism rates in the mangrove crab Ucides cordatus (Decapoda: Ocypodidae) under laboratory conditions. Aquaculture Research, v. 39, p. 263-267, 2008.

VIEIRA, R. H. S. F.; LIMA, E. A.; SOUSA, D. B. R.; REIS, E. F.; COSTA, R. G.; RODRIGUES, D. P. Vibrio spp. and Salmonella spp., presence and susceptibility in crab Ucides cordatus. Revista do Instituto de Medicina Tropical de São Paulo, v. 46, n. 4, p. 179-182. 2004.

WOLFF, M.; KOCH, V.; ISAAC, V. A trophic flow model of the Caeté mangrove estuary (North Brazil) with considerations for the sustainable use of its resources. Estuarine, Coastal and Shelf Science, v. 50 , p. $789-803.2000$.

ZANDERS, I. P.; MARTELO, M. The influence of acclimation temperature on magnesium and sulphate regulation in two mangrove crabs. Comparative Biochemistry and Physiology - Part A: Physiology, v. 78, n. 3, p. 487-492. 1984. 